\title{
Impact of anti-poaching approaches for the success of Rhino conservation in Chitwan National Park, Nepal
}

\author{
D. Mahatara ${ }^{1 *}$, S. Rayamajhi ${ }^{2}$ and G. Khanal ${ }^{3}$
}

\begin{abstract}
Nepal has succeeded in granting better protection for its Asian rhino population that has become exemplary in the world. Effective law enforcement along with community participation has been acclaimed as a reason for this achievement. However, there have been very few studies to assess the effectiveness of current anti-poaching strategies. In this study, we assessed the performance of SMART patrolling and population trend of rhino in Chitwan National Park (CNP). The patrol data collected through patrolling logbooks were used to visualize the coverage of SMART in the CNP and its Buffer Zone by dividing it into $1 \mathrm{~km} * 1 \mathrm{~km}$ grid cell. Logistic regression models were used to analyze whether or not the patrol effort and patrol frequency correlate with the reduction in occurrences of illegal activities. A total of 6,593 patrols were conducted within the last fifteen months. Logistic regression models revealed that sites with a greater frequency of patrols, rather than the combined distance walked, had a lower probability of occurrence of illegal activities ( $\beta$ Patrol.frequency= $-8.6428 \& \beta$ Patrol.effort $=-4.1804$ ). This implies that patrol frequency was found more significant than patrol efforts in reducing prevalence of illegal activities in and around the CNP. The poaching activities were found high during insurgency period. The trend in rhino poaching was found to be decreased with increase in number of security posts, Community-based Anti-poaching Unit formation, conservation education and sweeping/camping operations. To maintain the continuous success in the long-run, it is crucial to regulate and enhance effective law enforcement capability and more advance techno-based modality in close coordination with stakeholders including community institutions.
\end{abstract}

Key words: Anti-poaching, one-horned rhino, patrol efforts, patrol frequency, SMART patrolling

$\Delta$ bout 133,968 hectares of forests were cleared from Tarai region of Nepal alone for the settlement as well as for the eradication of malaria during $1950 \mathrm{~s}$ and 1980s (HMG, 1988). After the eradication of Malaria during 1954, people from mid-hills shifted to lowland of Tarai region for settlement and agricultural expansion, which resulted to the destruction and fragmentation of the habitat altering the natural ecosystem and biodiversity (Smith et al., 1998). Most of the wild animals, especially large mammals are now restricted to the few pockets of small protected areas in a small number because of the ongoing fragmentation of its habitat (Pradhan, 2007).
Besides habitat degradation and loss of prey, large mammals like rhinoceros, tiger and elephant population severely depleted by poaching for traditional medicines as well as for entertainment to the rulers (Mills and Jackson, 1994). Poaching of wild animals including one-horned rhinoceros, tiger and prey species was widespread before the enforcement of National Parks and Wildlife Conservation Act 1973 and designation of Chitwan National Park (CNP) and had remained the serious problem throughout Nepal, including all of the protected areas (Maskey, 1998). During Rana Regime (1845-1947), large scale hunting was done every year by the Rana rulers who were in times accompanied by the Dukes, Viceroys, and

1. Forest Research and Training Center, Kathmandu*E-mail: honeystar73@gmail.com

2. Institute of Forestry, Pokhara Nepal

3. Department of National Park and Wildlife Conservation, Kathmandu 
Princes and also by the king of England. Though mega species in Nepal were protected from 1845, the members of ruling class not only hunted them but they at times made profit also by selling to animal collectors, and tigers could be shot legally by paying Rupees 500 prior to 1970 (Bhatta, 1977).

Poaching is one of the major threats to biodiversity conservation in Nepal. Not only poaching affects the population status and demographic structures of wild flora and fauna, it also means that the entire ecosystem functions are affected by the removal of a species (Chungyalpa, 1998). In Nepal, over 800 rhinos were believed to be living in the Chitwan valley until 1950 (Dinerstein, 1979) based on their head counts. The number of rhinoceros dropped to less than 100 at the mid 1960's because of poaching and habitat loss for agriculture (Adhikari et al., 1999) and ignorance of conservation significance. Chitwan National Park (CNP) was gazzeted as a park in 1973 and from then until 1998, 2.6 rhinoswere poached annually (Martin, 1998). At the peak of the insurgency period (1998-2006) army posts and law enforcement patrol was curtailed, which created favorable environment for poachers, as a result around 150 rhinos were poached (Martin and Martin, 2010). However, the cases of poaching declined from 2007 with the end of decade long conflict and now Nepal has achieved new milestone in its conservation history by slowing down the numbers of rhino poaching incidents to zero for few years which might be due to resume of the army posts again and effective patrolling. And also, from 2010-2014, there was SMART (Spatial Monitoring and Reporting Tool) patrolling in addition to handling of intelligence by Protection Unit, Nepal army/park staff as well as involvement of community based anti-poaching operation by local community institutions that resulted in decreasing trend of rhino poaching and has been successful to maintain almost zero till now except single incidence in 2011, 2013 and 2017.

Now, Nepal's rhino population has increased by $21 \%$ based on the rhino count data released by the Government of Nepal on May 5, 2015. According to that survey report, there are 645 rhinos in total as compared to the 2011 estimate of 534 rhinos in Nepal's rhino range landscape range in Tarai Arc Landscape (DNPWC/MFSC, 2015). In recent days, SMART patrolling has been transformed to more advanced system of technology-based realtime monitoring.

Studies have shown that increase in the number of army posts, high penalties for wildlife crime, involvement of the NGO's with local participation, establishment of crime control bureau, increase in revenue collection are the supporting factors for decline in rhino poaching in Nepal (Martin et al., 2013). During the Maoist insurgency from 1995 to 2006, the army withdrew many of the scattered posts from Chitwan NP, Bardia NP and Suklaphanta Wildlife Reserve to concentrate their men for greater security. According to Martin and Martin (2010), shift of the army and the park staff from the core area and reduction of the posts to just 32 in 2009 were the main causes of massive loss of rhinos in the CNP.

However, many previous studies do not give clear figure regarding the influence of law enforcement patrolling guided by reports from local informants or community based anti-poaching, so in this study we try to analyze the impact of law enforcement interventions for rhino conservation. Linkie et al.(2015) figured out that understanding the ability of current strategies to suppress the patterns of illegal activities over space and time is critical to prevent the implementation of well-intended but ineffective strategies and ongoing losses of rhinos.

Continuity of success story of zero poaching is still challenging until and unless the modality or approach used to combat poaching is sustainably implemented and institutionalized. Through this study, we have assessed the performance of the existing modality used for current anti-poaching operations of rhino in the CNP, which helps to bridge the research gap and to develop adaptive management strategies. We have analyzed the performance of patrolling to decline the illegal activities and also figured out the past 10 years activities in order to decrease and increase the number of rhinos. From this study, we have recommended the park authorities and other conservationists to make priority for particular anti-poaching activities in order to sustain the present success in rhino conservation.

\section{Materials and methods}

\section{Study area}

The study was conducted in CNP which is situated 
in south central Nepal (Fig. 1), covering 932 sq. $\mathrm{km}$. in the subtropical lowlands of the inner Tarai. The geographic location of the park is between $\mathrm{N} 27^{\circ} 34^{\prime} 23^{\prime \prime}$ and $27^{\circ} 68^{\prime}$ '98' latitude and E $83^{\circ}$ $87^{\prime} 79^{\prime \prime}$ and $84^{\circ} 74^{\prime} 30^{\prime \prime}$ longitude whereas the geographic location of buffer zone is between $\mathrm{N}$ $27^{\circ} 28^{\prime} 23^{\prime \prime}$ and $27^{\circ} 70^{\prime} 38^{\prime \prime}$ latitude and E $83^{\circ} 83^{\prime}$ ' $98^{\prime \prime}$ and $84^{\circ} 77^{\prime} 38^{\prime \prime}$ 'longitude (CNP management plan, 2012-2016). The altitudinal range is from about $100 \mathrm{~m}(330 \mathrm{ft})$ in the river valleys to $815 \mathrm{~m}$ $(2,674 \mathrm{ft})$ in the Chure hills (Bhuju et al., 2007). The park shares its eastern boundary with the Parsa National Park, southwest part with Narayani River, northern with Rapti River and Reu River in the south. The topography of the CNP is quite diverse and unique with flood plains, river valleys and gorges and Churia hills. The floral diversity of the park consists of more than 600 plant species which include 3 gymnosperm, 13 pteridophytes, 415 dicotyledons, 137 monocot, 16 species of orchids (UNESCO/IUCN, 2003). The park harbors a more than 55 species of mammals, over 600 species of birds and 55 species of reptiles and amphibians (DNPWC/MFSC, 2013).

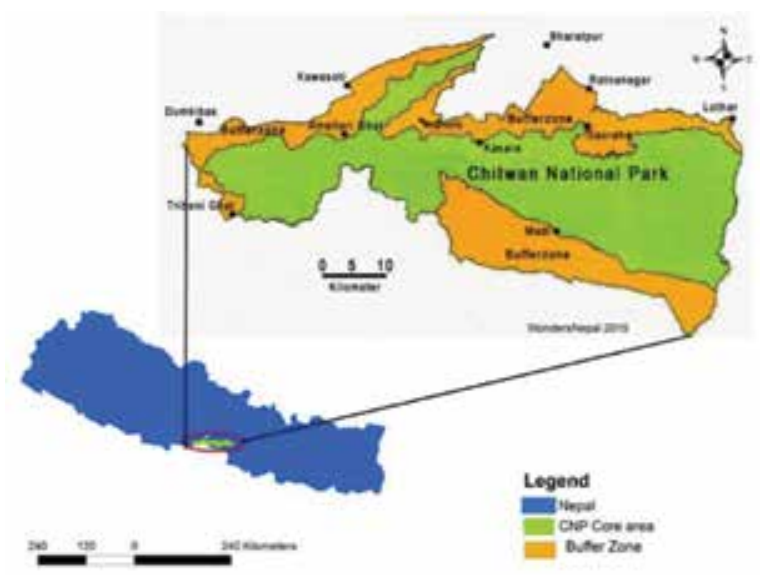

Fig. 1: Map showing Chitwan National Park and its buffer zone

\section{Methodology}

The study was primarily based on secondary data which were analyzed using different techniques. Ten years annual and monthly reports regarding anti-poaching activities were taken as a major source of information. Besides, records of legal cases of the CNP, various published and unpublished documents, reports, annual reports of different stakeholders, journals, articles and other relevant literatures were reviewed during the study. To study the efficiency of SMART patrol, patrolling logbooks and ranger data sheets collected from each of the 53 anti-poaching units were considered.

\section{Database for the study of SMART patrol}

To create a database from the analysis, the CNP and its buffer zone (BZ) area was divided into 1 $\mathrm{km} * 1 \mathrm{~km}$ grid cell using GIS tools because in general this is the average distance that a hunter or a patrol team might cover in a day. Each of these grid cells constituted a sampling unit for this study (Hines et al., 2010). The detail patrol data from each of the 53 park posts and army camp of the CNP was then collected. Each of these patrolling camps was fallen under one of the sampling units that were used for this study. The data from each of these anti-poaching units included the distance $(\mathrm{km})$ patrolled per year, number of patrols conducted per year and travel routes for each of those patrols to deter various illegal activities. Then these data were used to know the coverage of the park and its BZ by the patrol units and also to figure out the probability of occurrence of illegal activities with patrol frequency and patrol efforts. Detection of snares traps or tools used for rhino hunting, rhino poaching cases revealed, poachers arrested and rhino shot dead incidence reported from the beginning of implementation of SMART patrolling in every anti-poaching camps was included as illegal activities. However, poachers were very rarely encountered in person by a patrol team except other invaders. Therefore, the effectiveness of law enforcement patrolling was assessed using an occupancy framework that accounts for imperfect detections (MacKenzie et al., 2002).

$>$ Patrol frequency- number of times that each patrol team of an anti-poaching camp visited and area covered.

$>$ Patrol efforts- number of kilometers patrolled by each of the patrolling team of anti-poaching camps.

The statistical analysis was based on the logic that the law enforcement patrols for the conservation intervention could stimulate the suppression of illegal activities through removing snare traps or tool sets for rhino poaching and deterring the unauthorized mobility inside the park and buffer 
zone area, which in turn could influence help to protect and comfort the status of rhinoceros.

The effectiveness of law enforcement patrolling was analyzed using logistic regression and the coverage of the SMART patrol was assessed using Arc GIS. Qualitative and quantitative data were analysed using SPSS 19.0 and MS Excel 2007 and presented in the tables, bar diagram and line chart.

\section{Results and discussion}

\section{SMART patrolling}

The intensive joint patrolling by Nepal army and park staff together on a regular basis and on the basis of reports from local informants is considered as a crucial factor for the decline of the poaching incidences. Patrol team layout their patrolling route based on the information provided by the informers, which are not only increased by their numbers but also trained effectively to improve their ways of collecting information on potential rhino poachers and traders. The data regarding illegal activities include detection of snares traps/ tools used for rhino hunting, finding out of rhino poaching cases, arrest of poachers, discovering of rhino shot dead incidence from the beginning of implementation of SMART patrolling in every anti-poaching units.

On an average, each patrol unit conducted one patrol per day which shows that there were around 20,000 patrols per year from 53 patrol units and these teams were successful to arrest as much as 176 offenders including rhino during the period of 2010-2015. The maximum patrol activities were recorded near and around the BZ (Fig. 3), where the poaching incidences were higher in the past than core area and patrol intensity was found high on thefringes of core area and the BZ which may be due to high accessibility of road networks.

Our study stresses the importance of expanding patrol coverage and augmenting this with a carefully cultivated and widespread informant network. Linkie et al. (2015) also found that sampling sites/grid cells with a greater frequency of patrols, rather than the combined distance walked (patrol effort), would have a lower occurrence of poaching cases in succeeding years.
Table 1: Rate of occurrence of illegal activities with Patrol Frequency \& Patrol Efforts

\begin{tabular}{|l|l|l|l|}
\hline Model & AIC Value & B1 & B2 \\
\hline $\begin{array}{l}\text { Logit(p)=(B1+B2)* } \\
\text { patrol frequency }\end{array}$ & 10.475 & 0.6153 & -8.6428 \\
\hline $\begin{array}{l}\text { Logit(p)=(B1+B2)* } \\
\text { patrol efforts }\end{array}$ & 20.186 & 0.3804 & -4.1804 \\
\hline
\end{tabular}

From logistic regression, both patrol frequency and patrol efforts are significant with occurrence of illegal activities i.e. with the increase in patrol frequency as well as patrol effort, the probability of occurrence of illegal activities declines (Fig. 2). Among them, patrol frequency has more negative relationship with occurrence of illegal activities ( $\beta$ Patrol. frequency $=-8.6428$ ) than with patrol effort and $\beta$ Patrol. effort $=-4.1804$ ) (Table 1) and this indicates that patrol efficiency is highly significant as compared to patrol efforts.

This shows that SMART patrolling team should be more focused to increase the patrol frequency. Unified patrolling involving community people, nature guide and park staff should be made more effective. It should not be only concentrated to park headquarter and BZ periphery but also inside the core area.Park staff especially rangers and game scouts should be equipped with arms so they can patrol themselves with greater security.

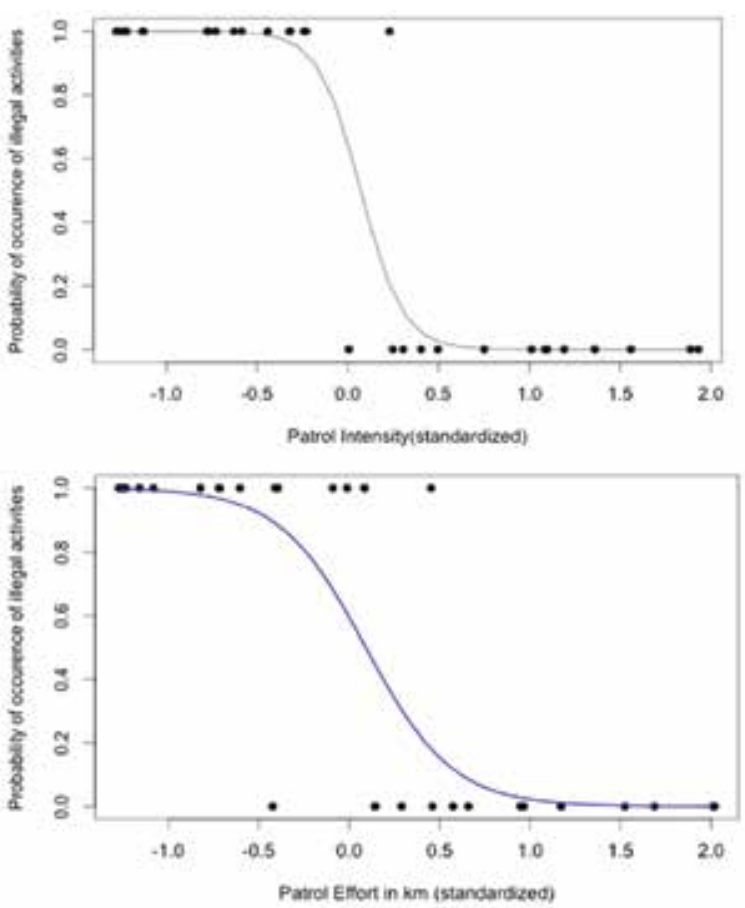

Fig. 2: Rate of occurrence of illegal activities with patrol intensity and patrol effort 
The figure 2 shows that both patrol frequency and effort have significant relationship with the probability of occurrence of illegal activities, however, the graph indicates that illegal activities drop faster with increase in patrol frequency than patrol effort.

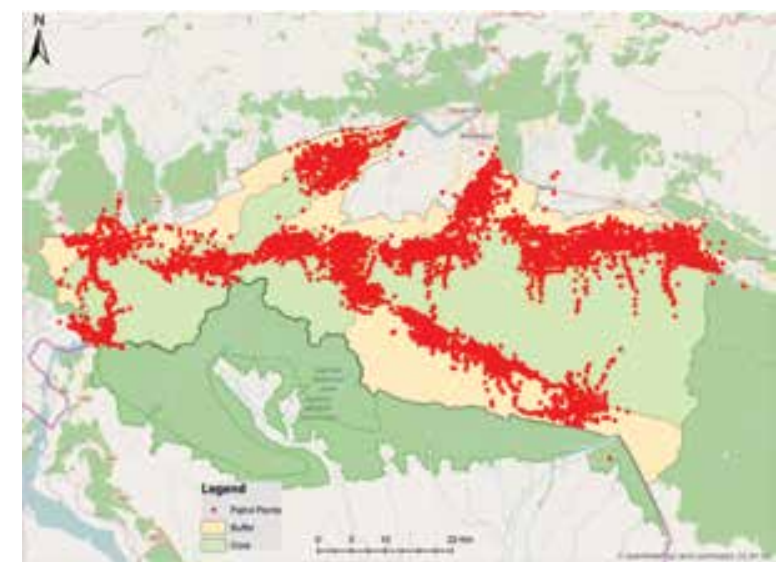

Fig. 3: Map showing the coverage of SMART patrolling in CNP

\section{Increase in security posts}

Earlier, during the Maoist insurgency from 1995 to 2006 , the army field camps were with drawn from the CNP to concentrate their men for high security. For instance, at the peak of insurgency period from 2001-2005, the army and the park staff had only sevenout posts in the CNP which resultedin significant loss of wildlife and other biological resources. In the CNP in late 2009, the army and the park staff had only 32 posts which was the main cause of massive loss of rhinos in the CNP (Martin and Martin, 2010).

Martin et al. (2013) concluded that the re-occupy of more previousarmy posts by Nepal army in the CNP is the vitally determinant to decline poaching incidences. Our results also showed that the incidences of poaching cases declined with the re-establishment of security posts within the CNP from 2007 (Fig. 4). The main policy change that brought dramatic improvement in the rhino conservation approaches is the operational shift in anti-poaching strategy. MIST, a unified database management system designed as a full suite of tools and services for conservation,applies the technology-based law enforcement real-time SMART monitoring system designed by the wildlife conservation society (Thapa et. al., 2013)which provides regular and rapid communication of information on illegal activities and other reports of protected area.

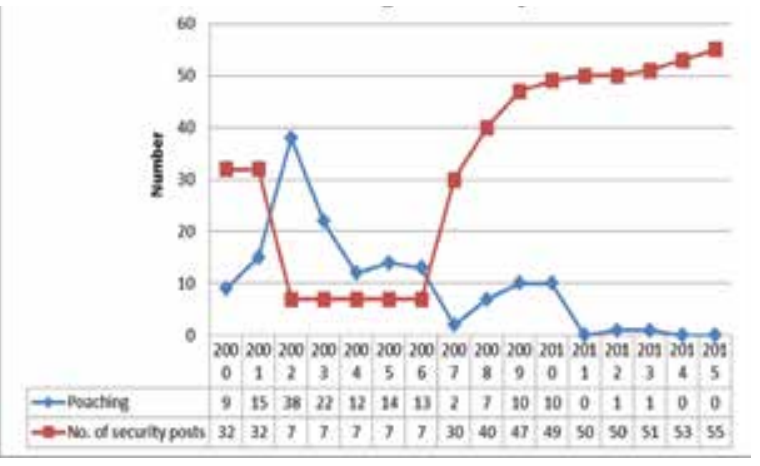

Fig. 4: Rhino poaching vs. security posts in CNP

Increase in the security posts has negative correlation with rhino poaching number.The figure 4 shows that the maximum rhino poaching was in 2002 due to decrease in the number of security posts and very few poaching incidents were detected as the number of security posts increased only from 2009.

It showed that the upsurge of rhino poaching from 2001 to 2006 was disappointedly increased, as the army decreased its soldiers within the CNP to prevent Maoist attacks on them. The army decided to withdraw 25 posts to concentrate their soldiers to only eight guard posts along with the government's declaration of emergency and with increasing threats of Maoist attack, which made easier for poachers to violate the legal procedures and operate poaching in and around the CNP and there was loss of around 100 rhinos from 20012007.

\section{Arrest of rhino poachers}

Arrest of offenders, whocommit the wildlife crime, is another one of the major activities of the CNP. Through cooperative joint effort of park and army staff, 51 rhino poachers and traders were arrested during 2010/2011 in and around the CNP, which is the highest number of offenders arrested in case of rhino poaching till date. In October 2012, officials arrested an entire chain of rhino poaching gang. The poaching gang consisted of 17 people, all were arrested from the Chitwan area, including two women in the gang, being less likely to suspect though. 


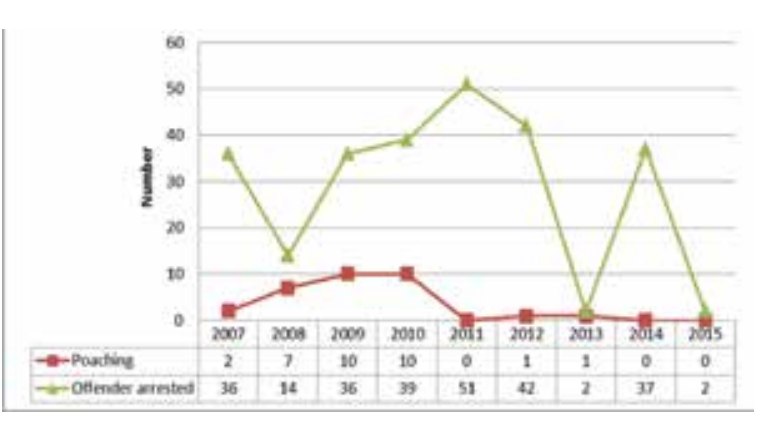

Fig. 5: Number of rhino poachers arrested vs. rhino poaching

There was no poaching incident in 2011 as the number of offenders arrested in that year was maximum in comparison to other years. The CNP arrested more than 250 rhino poachers within the last nine years (Fig. 5). The government of Nepal has stepped up efforts against dismantling the network of poachers and wildlife criminals within and outside the protected areas through its enforcement agencies and collaboration with conservation partners such as WWF and local communities. The capture and jailing of Nepal's most wanted poacher show how serious the government is about tackling wildlife crime and this results the decline in poaching activities.

\section{Impact of conservation education}

The BZ concept was promulgated for Nepal's protected areas in 1993 by an amendment to the National Parks and Wildlife Conservation Act of 1973 to help the local community who are relied on $\mathrm{BZ}$ products rather than park resources and to gain their support for conservation. The BZs were mostly funded by $30-50 \%$ of the revenue raised by the respective protected areas (Baral et al., 2007). Out of the total budget allocated for BZ, the Buffer Zone Management Committee (BZMC) in Chitwan allocates $30 \%$ for capacity enhancement and conservation education (especially for anti-poaching operations, awareness, youth mobilization and formal and informal education) which significantly helps to conserve rhino and other wildlife. Martin et al. (2013) also showed that the co-operation of NGO with local people living near the fringes of the protected areas is the key step to harmonize them to ensure the protection of rhino population.

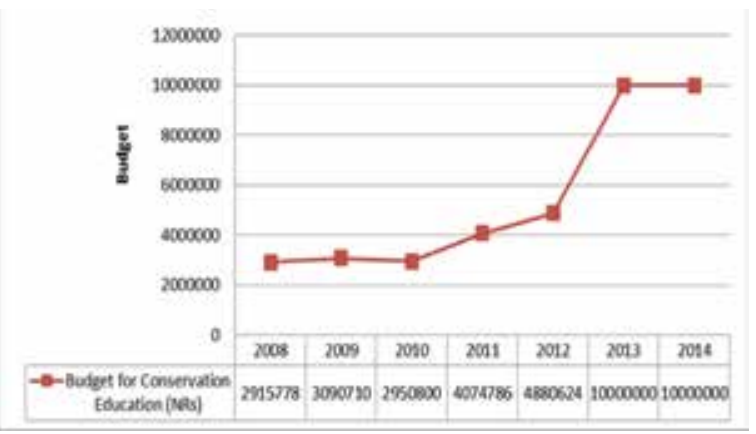

\section{Fig. 6: Budget for conservation education in} different fiscal years

In general, the budget for conservation education was found in an increasing trend from 2008, after the end of a decade long conflict in the country. The money allocated for conservation education is often spent on projects to capacitate and aware the local community about the importance of protecting wildlife, especially rhinos, and to get actively involved in the wildlife conservation with due responsibility and stewardships. Community instructors visit schools to teach the youth about the importance of conservation and also to recruit youth into anti-poaching mission, which has helped to decline the rate of park-people conflict with win-win situation and finally to achieve the positive results in the conservation of rhino.

\section{Special operation: Sweeping and camping operations, short- and long-range patrolling, operation Maha-Hunt}

One of the new strategies adopted in recent days is 'sweeping operation'. It puts together a large group of men from the park and army to patrol intensively when a problem is perceived. The patrollers use some of the park's domesticated elephants, motor vehicles, motor boats and bicycles. The men may stay out for a week, camping in 'hot spots' where rhino poaching is likely to occur.

Sweeping/camping operation is specially conducted in suspected areas which are highly vulnerable in terms of wildlife poaching and other illegal activities and also in those areas where there is difficulty for regular patrol by vehicles especially during monsoon. The number of staffs in the sweeping/camping team was found to be varied based on the location and information. Each sweeping and camping operation consisted of five to seven army personnel, two Park staff 
and six elephant staff regularly and sometimes 10-20 elephantswereused to sweep the larger area.

The CNP intensified efforts to curb wildlife poaching in the region with an operation involving a special security force deployed by Nepal army. The campaign named 'Operation Maha Hunt' runs till May each year as animals particularly the Royal Bengal Tiger and One-horned Rhino in this park are at high risk of falling prey to poachers during November to May each year. A joint team from the special force and the CNP-based Batuk Dal Battalion were trained for the operation. Winter is marked as sensitive season for poaching wild animals in the CNP with open tourist path accessible to its inner part and the BZ, the forests becoming deserted and the access of people's easy movements with receding river water levels. The CNP conducted about 225 sweeping/camping operations from 2007 to 2014 (Fig. 7).

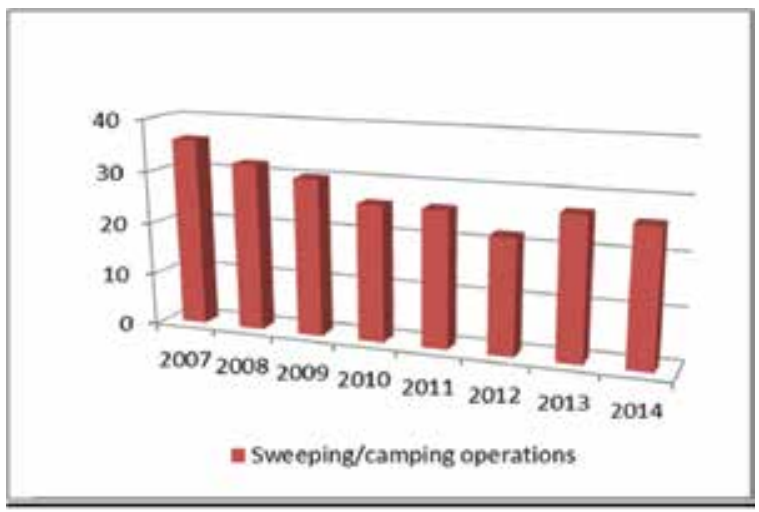

Fig. 7: Sweeping/camping operations in CNP

Basically, sweeping and camping operations were carried out on the basis of local informants and at the hotspots where the probability of detection of illegal activities was high and consequently it helpedin decrease in the number of poaching incidents due to the risk factor for offenders.

\section{Community approach}

In almost all of the countries around the world where poaching exists, there have been the antipoaching teams to act as a counter measure. As poaching increased, the youth became more concerned about the issue and organized themselves in groups in an effective way to lessen illegal poaching, thus brought about to the establishment of the Community-based
Anti-poaching Unit (CBAPU) concept. The CBAPU is as a sub-committee of Buffer Zone User Committee (BZUC). The CBAPU, a loose forum of youths for conservation initiative, aims to motivate and engage local youths in conservation, plays a crucial role in collecting information about the poaching activities and controlling illegal activities. Regular training and capacity enhancement programs are important to mobilize them effectively in wildlife conservation. Realizing this, 22 CBAPUs were formed for the effective implementation and to address the various issues of community, and now they are effectively functioning in Chitwan. The CBAPUs are replicated to other parts of the country also. To meet the objective of the CBAPU mission, local youths are main streamed in the institutional mechanism with their active participation to minimize the human wildlife conflict, forrescuing of problem animal and quick response at community. Rapid Response Team (RRT) of five members in each CBAPU is also working in the team.

The major activity of the CBAPO is to aware the local communities and eco-clubs about protection of wild animals from poaching and curbing illegal wildlife trade. Awareness programs are held on regular intervals. These include street dramas, house-to-house visits, distribution of pamphlets and posters, rallies, hoarding boards and games such as football and marathon. Additionally, as most of the local people were ignorant of conservation and formal education, an effective way of attracting their attention could be through popular folk songs, who are dedicated to wildlife conservation. Radio programs, in Tharu and Nepali languages, are also aired regularly. The poachers offer money to the indigenous people of the region like Majhi, Mushar and Bote in order to assist them as their daily lives and cultures are directly linked with wild animals. Interaction programs with them are therefore important in making them understand the significance of saving wild animals.

In this way, the CBAPOs are playing a very effective role in controlling poaching and illegal wildlife trade in their locations through regular patrolling, keeping vigilance on poachers and traders, and collecting information on criminals and furnishing the same to the enforcement agencies for timely action. They are playing 
crucial role in generating awareness to the public and providing information to enforcement agencies to control wildlife crime.

\section{Conclusion}

This study indicated that most of the poaching activities of rhino in the CNP were observed during the insurgency period. Nepal lost 177 rhinos from poaching in the CNP between 1997/98 and 2010/11 (DNPWC/MSFC, 2011). However, the combined efforts of different stakeholders including across the park and buffer zone boundary initiatives and the stringent enforcement of country's law (conservation education, increase in security posts, CBAPU mobilization, increase in total revenue collection, successful rate of arresting offenders, sweeping and camping operations) are seen as major effective tools adopted by the CNP to grab the success of zero-poaching. Also, the introductions of MIST and SMART patrolling using real time monitoring for regular patrolling are major tools adopted by the park and Nepal army protection unit to decline poaching activities.

In order to maintain this achievement, it is recommended to focus on increased patrol frequency by covering the maximum area of the national park and anti-poaching units should be made more effective in grass root level in and around the national park and buffer zone to strengthen the collaborative way of conservation with benefit sharing mechanism. Close coordination, collaboration and cooperation mechanism should be regularly encapsulated with other concerning government, security and non-government agencies, conservation partners, local community institutions, and transboundary counterparts.

\section{Acknowledgements}

This paper is a part of the author's B. Sc. thesis dissertation at Institute of Forestry, Pokhara Campus. We are obliged to the National Trust for Nature Conservation (NTNC) for providing financial support to accomplish this study. We sincerely thank Department of National Park and Wildlife Conservation for allowing permission to conduct the research and also to the Chitwan National Park family for their support in data collection during field work.

\section{References}

Adhikari, T. R., Pradhan, N. M. B. and Poudel, N. 1999. A Strategy to Combat Poaching in Chitwan Valley. Department of National Parks and Wildlife Conservation, Kathmandu, Nepal.

Baral, N. and Heinen, J. T., 2007. Resources use, conservation attitudes, management intervention and park-people relations in the Western Terai landscape of Nepal. Environmental conservation, 34 (1), pp.64-72.

Bhatta, D. D. 1997. Natural History and Economic Botany of Nepal.

Bhuju, U. R., Shakya, P. R., Basnet, T. B. and Shrestha, S., 2007. Nepal biodiversity resource book: protected areas, Ramsar sites, and World Heritage sites. International Centre for Integrated Mountain Development (ICIMOD).

Chungyalpa, D. 1998. Anti-poaching operations: A report on anti-poaching operation in RBNP, RCNP, PWR, SWR (1992-1998). WWF Nepal Program, Kathmandu, Nepal.

Dinerstein, E., 1979. An ecological survey of the Royal Karnali-Bardia wildlife reserve, Nepal. Part II: habitat/animal interactions. Biological Conservation, 16 (4), pp.265-300.

DNPWC/MFSC. 2011. Annual Report, 2011. Department of National Park and Wildlife Conservation, Ministry of Forests and Soil Conservation, Kathmandu, Nepal.

DNPWC/MFSC. 2013. Annual Report, 2013. Department of National Park and Wildlife Conservation, Ministry of Forests and Soil Conservation, Kathmandu, Nepal.

DNPWC/MFSC. 2015. Annual Report, 2015. Department of National Park and Wildlife Conservation, Ministry of Forests and Soil Conservation, Kathmandu, Nepal.

Hines, J. E., Nichols, J. D., Royle, J. A., MacKenzie, D. I., Gopalaswamy, A. 
M., Kumar, N. S. and Karanth, K. U., 2010. Tigers on trails: occupancy modeling for cluster sampling. Ecological Applications, 20 (5), pp.1456-1466.

HMG. 1988. Master Plan for the Forestry Sector of Nepal. Main Report. Ministry of Forests and Soil conservation, Kathmandu, Nepal.

Linkie, M., Martyr, D. J., Harihar, A., Risdianto, D., Nugraha, R. T., Leader-Williams, N. and Wong, W.M., 2015. EDITOR'S CHOICE: Safeguarding Sumatran tigers: evaluating effectiveness of law enforcement patrols and local informant networks. Journal of Applied Ecology, 52 (4), pp.851-860.

MacKenzie, D. I., Nichols, J. D., Lachman, G. B., Droege, S., Andrew Royle, J. and Langtimm, C. A., 2002. Estimating site occupancy rates when detection probabilities are less than one. Ecology, 83 (8), pp. 2248-2255.

Martin, E., 1998. Will new community development projects help rhino conservation in Nepal ? Pachyderm, 26, pp. $88-99$.

Martin, E. and Martin, C., 2010. Enhanced community support reduces rhino poaching in Nepal. Pachyderm, (48), pp. 48-56.

Martin, E., Martin, C. and Vigne, L., 2013. Successful reduction in rhino poaching in Nepal. Pachyderm, 54, pp.66-73.
Maskey, T. M., 1998. Sustaining anti-poaching operations and illegal trade control. WWF Nepal Program Report Series, 37.

Mills, J. A. and Jackson, P., 1994. Killed for a cure: a review of the worldwide trade in tiger bone. Cambridge: Traffic International.

Pradhan, N. M. B., 2007. A Landscape Approach in Conserving Large Mammals: A Case Study from Western Terai, Nepal. The Initiation, 1, pp. 44-55.

Smith, J. L. D., Ahearn, S. C. and McDougal, C., 1998. Landscape analysis of tiger distribution and habitat quality in Nepal. Conservation Biology, 12 (6), pp. 1338-1346.

Thapa, K., Nepal, S., Thapa, G., Bhatta, S. R. and Wikramanayake, E., 2013. Past, present and future conservation of the greater onehorned rhinoceros Rhinocerosunicornis in Nepal. Oryx, 47 (3), pp. 345-351.

UNESCO/IUCN. 2003. Enhancing Our Heritage Project: Monitoring and Managing for success in Natural World Heritage Sites. Initial Management Effectiveness Evaluation Report, Royal Chitwan National Park, Nepal, August 2003. 